\title{
The economic performance of Swiss drinking water utilities
}

\author{
Anne-Kathrin Faust · Andrea Baranzini
}

Published online: 17 April 2013

(c) Springer Science+Business Media New York 2013

\begin{abstract}
This paper measures the performance in terms of costs of Swiss drinking water utilities accounting for environmental factors. We estimate a translog stochastic variable cost frontier using two different techniques on an unbalanced panel of 141 water distribution utilities over the years 2002-2009, for a total of 745 observations. Results show that exogenous factors have an impact on variable cost. More precisely, we find that the share of pumped over total extracted water, population density, altitude and meteorological factors (maximum 30 days temperature and extreme precipitation events) have a significant impact on variable cost. Likelihood ratio tests emphasize the importance to include observed heterogeneity in the estimations. Efficiency rankings provided by models accounting for exogenous factors and their counterparts without them are however relatively similar. On the contrary, the efficiency ranks differ strongly between alternative estimation techniques. In assessing the economic performance of utilities, the most important choice thus seems to be about the way unobserved heterogeneity is treated.
\end{abstract}

Keywords Stochastic frontier analysis - Environmental factors $\cdot$ Heterogeneity $\cdot$ Drinking water distribution

A.-K. Faust ( $₫)$

Research Group on the Economics and Management of the Environment (REME), Ecole Polytechnique Fédérale Lausanne, EPFL ENAC INTER REME, Bat. BP, Station 16,

1015 Lausanne, Switzerland

e-mail: annekathrin.faust@gmail.com

\section{A. Baranzini}

Haute École de Gestion de Genève - Geneva School of Business

Administration (HEG Ge), University of Applied Sciences

Western Switzerland (HES SO), 7 route de Drize,

1227 Carouge-Genève, Switzerland
JEL Classification C23 $\cdot$ D24 $\cdot$ L25 $\cdot$ L95 $\cdot$ Q25

$\begin{array}{ll}\text { Abbreviations } \\ \text { BC } & \text { Battese and Coelli } \\ \text { DEA } & \text { Data envelopment analysis } \\ \text { FTE } & \text { Full time equivalent } \\ \text { PL } & \text { Pitt and Lee } \\ \text { SFA } & \text { Stochastic frontier analysis } \\ \text { SGWA } & \text { Swiss Gas and Water Industry Association } \\ \text { TRE } & \text { True random effect }\end{array}$

\section{Introduction and context}

Growing concerns about the performance of network industries as well as climate change are challenging drinking water distribution utilities and triggering interest in their production structure and efficiency. The determinants of cost and efficiency need to be explored to provide drinking water of the highest quality at minimum possible cost. Indeed an increasing literature seeks to determine economies of density, scale and scope to judge water industry market structure (Carvalho et al. 2012). The comparison of the cost and performance of private and public companies has also attracted particular attention (Walter et al. 2009). Today, many countries are using various regulatory schemes that involve benchmarking of water distribution utilities to enhance performance, for example the United Kingdom, Australia or the Netherlands (de Witte and Marques 2010). Measuring the efficiency of water distribution utilities is thus a major challenge. Particularly, given that drinking water utilities typically face very diverse environmental conditions, the assessment of 
their performance has to account for the impact of exogenous factors and unobserved heterogeneity. Exogenous or environmental factors characterise the operational environment in which the drinking water utility operates: they cannot be controlled by the management, but have an impact on its costs and performance. As shown by the literature reviews of Renzetti and Dupont (2003), Conti (2005), Abbott and Cohen (2009), Walter et al. (2009) and Berg and Marques (2011) there are a range of exogenous factors which impact the technology and the performance of water distribution utilities, such as population density, the regulatory context, water input source, customer type, water quality and local topography. Some recent studies that are particularly dedicated to the assessment of the role of exogenous factors in the estimation of the efficiency of water utilities also highlight the necessity to include those environmental factors in the analysis. Carvalho and Marques (2011) employ non-parametric estimation techniques to evaluate the influence of the operational environment on the efficiency of water utilities in Portugal. They find regulation, the share of purchased and surface water, customer density, peak factor and the percentage of residential customers to be significantly related to the performance of water utilities. Picazo-Tadeo et al. (2009a, b) investigate the role of environmental factors in water utilities' technical efficiency in Andalusia. Private outperform public utilities, and firms located in highly and densely populated areas have a higher technical efficiency. Utilities providing water services to tourist municipalities also exhibit efficiency levels that differ from those in other areas. Marques et al. (2011) investigate the influence of exogenous factors on the performance of water utilities in Japan with data envelopment analysis (DEA). They find significant links between efficiency and peak factor, water consumption per capita, prefecture GDP and subsidization. Zschille and Walter (2012) estimate the performance of German water utilities with both parametric and non-parametric techniques. Groundwater input, share of water losses, output density, elevation differences, per capita debt in the municipality, eastern location, private governance and provision of sewage services impact efficiency. While many studies now include environmental factors, research on the impact of meteorological factors is still sparse. Renzetti and Dupont (2009) include maximum weekly summer temperature and total precipitation in the estimation of the efficiency of water utilities in Ontario in 1996. They find that those meteorological factors are associated with increased inefficiency.

Switzerland is an interesting case of study. Although there seems to be a general consensus that the Swiss water sector has to be preserved from liberalization pressures which are presently acting in other network industries, there is nevertheless a growing concern about their performance and the relatively small size of many of the utilities (cf. Kilchmann 2003). Switzerland is classified as a high water availability country, but regions and thus drinking water utilities face very diverse conditions, constraints and management structures. In particular, population density, climatic, topographic and water conditions are very different from one region to the other. Even though it is a small country, weather conditions can be very different. Particularly, temperature varies between mountainous and plain regions and from year to year. Climate change is expected to increase the frequency of heat waves, a phenomenon that already occurred in 2003 and 2006 summer periods. Moreover, heavy precipitation episodes may increase in the future. These are mostly local and often do not affect the whole country, but rather specific small regions, thus impacting some water utilities while sparing others.

Since Switzerland is a federal state, the responsibility of water supply is divided between the federal, cantonal and municipal levels (for a detailed discussion of water institutions in Switzerland, see Luís-Manso 2005). The Confederation mainly sets the legal framework for water protection and drinking water quality standards, with a limited role in the financing of infrastructures for water protection. Contrary to other countries, except for quality standards, there is no central water regulator, although there is a price supervisor who can express recommendations on water price levels. Drinking water provision and control are thus mostly within the competence of the Cantons, which however generally delegate those responsibilities to various degrees to the municipalities. As a result, the Swiss drinking water market is highly segmented, characterized by a very large number of water utilities operating in a very heterogeneous context, acting as local monopolies very often controlled by the municipalities. The Swiss drinking water distribution industry thus provides a very interesting framework to study the impact of both observed and unobserved heterogeneity on cost and performance.

Recently, there has been a surge in literature related to the analysis of the cost and performance of the drinking water sector, reflecting worries about market structure and performance. European examples outside the United Kingdom include the studies discussed above for Germany, Portugal and Spain, and further work about the Netherlands (de Witte and Saal 2010; de Witte and Dijkgraaf 2010), France (Garcia et al. 2007), Italy (Abrate et al. 2011; Di Cosmo 2012) and Slovenia (Filippini et al. 2007). On the contrary, the Swiss water distribution sector has received little attention in the literature. To our knowledge, there is only a study by Farsi and Filippini (2009) analysing the performance of 34 Swiss water multi-utilities for the years 1997-2005. They estimated stochastic cost frontiers accounting for population density, which the authors find to 
have a positive impact on the marginal cost of water distribution.

Our paper adopts a parametric approach and estimates a stochastic cost frontier to measure the efficiency of Swiss drinking water utilities, accounting for differences in environmental constraints. Its contributions are threefold. First, it accounts not only for customer density, water type, or regional environmental factors, but it also analyses the impact of weather-related factors on cost and performance, an issue that has received little attention yet. Second, it measures the efficiency of Swiss drinking water distribution utilities, using an unexploited database of the Swiss Gas and Water Industry Association (SGWA). Third, it compares alternative estimation techniques to treat both observed and unobserved heterogeneity. The structure of the paper is the following. Section 2 discusses the model specification and empirical implementation. Section 3 defines the variables and presents the descriptive statistics of the sample. Section 4 discusses the results, and finally Sect. 5 concludes.

\section{Model specification}

To analyse performance, the literature proposes various parametric and non-parametric methodological approaches, the two most common being stochastic frontier analysis (SFA) and DEA. Both have their strengths and shortcomings and have been used to study the efficiency of water distribution utilities in various contexts. We use SFA, independently introduced by Aigner et al. (1977) and Meeusen and van den Broeck (1977), to estimate the variable cost frontier and efficiency scores of Swiss drinking water utilities. The main weakness of SFA is that it calls for distributional assumptions on the error terms, as well as a functional form for the cost frontier. These can have an important impact on results, while particularly the appropriateness of the distribution of error terms is difficult to ascertain. However, in the context of our study, SFA offers some important advantages over alternative techniques. Firstly, measurement errors and random shocks are accommodated in SFA, and the technique is consequently less sensitive to outliers. Secondly, it easily allows for statistical hypothesis testing. Thirdly, SFA proposes solutions to distinguish between unobserved heterogeneity and inefficiency and to deal with both observed and unobserved heterogeneity in a one-step procedure.

We estimate a variable rather than a total cost frontier, because the latter supposes that the producers are at their long term equilibrium and that they use their production factors at the level minimizing total cost. In the case of water utilities, such an assumption is relatively strong, in particular with regard to their capital stock, which may not be at its optimal level for two main reasons (Baranzini
1996). Firstly, modifications in the capital stock are relatively costly and thus the size of the main water utilities infrastructures is typically based on demographic and economic forecasts, which can be wrong. Secondly, water utilities are obliged to respond to all the demand, and thus they typically dispose of excess capacities to account for seasonal and unexpected demand variations (e.g. in case of fire). For those reasons, the capital stock of the water utilities can be considered fixed in the short term and only adjusting partially with respect to its long term equilibrium. The stochastic variable cost frontier can be expressed in general terms as:

$\ln \mathrm{VC}_{\mathrm{it}}=\mathrm{c}\left(\mathrm{y}_{\mathrm{it}}, \mathrm{p}_{\mathrm{it}}, m_{i t}, z_{i t} ; \beta\right)+\mathrm{v}_{\mathrm{it}}+\mathrm{u}_{\mathrm{it}}$

where $\mathrm{VC}_{i t}$ are the variable costs of firm $i$ at time $t, y_{i t}$ the output, $p_{i t}$ the vector of factor prices, $m_{i t}$ the quasi-fixed input, $z_{i t}$ the exogenous (environmental) factors and $\beta$ the vector of coefficients to be estimated. The $v_{i t}$ is a random error term measuring white noise, while $\mathrm{u}_{\mathrm{it}}$ is a non-negative random variable interpreted as the cost inefficiency measure. $u_{i t}$ must take positive values, because firms cannot operate below the cost frontier.

The cost frontier does not only include output, price and quasi-fixed input variables, but accounts for the environment in which the firms operate. Environmental variables can be included in the estimated model following two different approaches (e.g. see Coelli et al. 1999).

The first approach assumes that the exogenous variables have a direct impact on the cost frontier, affecting the technology and the production structure, and therefore the shape of the frontier. Environmental factors are thus directly included into the cost frontier. In this approach, every firm faces a different frontier, or benchmark, depending on the environment in which it operates, and the resulting inefficiency scores are net of environmental influences. In other words, by including the exogenous factors directly in the frontier, the level of the cost frontier is adapted to the environmental conditions of the utility. For example, a utility faced with a particularly hostile environment will be confronted with a scaled-up cost frontier, thus lowering its inefficiency score. The environment impacts performance by altering the structure of the cost frontier and not efficiency levels, as it is assumed uncorrelated to them (Kumbhakar and Lovell 2000). This approach has among others been used by Filippini et al. (2007) in their study on the cost efficiency of the Slovenian water distribution utilities, by Abrate et al. (2011) in their paper about the cost efficiency of the Italian water service and by Zschille and Walter (2012) to analyse the performance of water distribution utilities in Germany.

The second approach assumes that exogenous variables do not directly influence the frontier, but rather impact the cost-inefficiency score. Consequently, in this approach the 
environment does not affect the technology, a strong assumption in heterogeneous sectors: all the firms share an unique cost frontier and are evaluated against the same benchmark. The exogenous variables are modelled to influence the distribution of the $\mathrm{u}_{\mathrm{it}}$ and therefore the distance that separates the firms from the benchmark. Their effect is included in the inefficiency scores, which consequently are gross values. This approach was developed by Kumbhakar et al. (1991), Reifschneider and Stevenson (1991), Huang and Liu (1994) and Battese and Coelli (1995) and it has for example been chosen by Fraquelli and Moiso (2005) in their study about the cost efficiency of the Italian water industry.

There are no compelling theoretical arguments to prefer one approach over the other. In this paper, we have opted for the first approach, allowing for the exogenous variables to directly influence the shape of the frontier. We indeed believe that the environmental background of the Swiss water utilities is so heterogeneous that it is likely to affect their technology and production structure, therefore commanding the inclusion of environmental factors into the cost frontier. Nevertheless, a model in which observed heterogeneity is included in the variance of the inefficiency is also estimated as a robustness check of the results.

In the empirical application it is then necessary to specify the functional form of the cost frontiers to be estimated. In the literature, several studies use a CobbDouglas cost function (e.g. Antonioli and Filippini 2001). Although its simplicity and easily interpretable results make it an attractive choice, the Cobb-Douglas specification imposes unnecessary restrictions on the production technology, in particular regarding economies of scale. For this reason, the majority of studies use a translog form, which is more flexible and also contains the CobbDouglas specification as a special case. The translog cost function, first introduced by Christensen et al. (1973), corresponds to a second degree Taylor approximation in the logarithms of an arbitrary cost function, with some restrictions in the parameters to respect the main desired economic properties (e.g. symmetry and homogeneity). The main disadvantage of the translog is related to its definition: since it is a local approximation, the results are reliable only close to the approximation point. ${ }^{1}$ For Swiss water utilities, we specify a one output, two input translog frontier, including six exogenous factors. To save degrees of freedom, the environmental factors are not interacted with the other variables, implicitly assuming separability

\footnotetext{
1 The globally flexible Fourier functional form (Gallant 1981) could offer an even more flexible solution. However, it would increase the number of parameters to be estimated and result in a further loss of degrees of freedom (Filippini et al. 2007), which is why it is not estimated in this paper.
}

between these factors and the other variables. ${ }^{2}$ The translog thus takes the following form:

$$
\begin{aligned}
& \ln \left(\frac{V C_{i t}}{p M A_{i t}}\right)=\alpha+\beta_{Y} \ln Y_{i t}+\beta_{p L} \ln \left(\frac{p L_{i t}}{p M A_{i t}}\right)+\beta_{c a p} \ln C A P_{i t} \\
& \quad+\frac{1}{2} \beta_{Y Y} \ln Y_{i t} \ln Y_{i t}+\frac{1}{2} \beta_{p L p L} \ln \left(\frac{p L_{i t}}{p M A_{i t}}\right) \ln \left(\frac{p L_{i t}}{p M A_{i t}}\right) \\
& \quad+\frac{1}{2} \beta_{\text {capcap }} \ln C A P_{i t} \ln C A P_{i t}+\beta_{Y p L} \ln Y_{i t} \ln \left(\frac{p L_{i t}}{p M A_{i t}}\right) \\
& \quad+\beta_{Y c a p} \ln Y_{i t} \ln C A P_{i t} \\
& \quad+\beta_{p L c a p} \ln \left(\frac{p L_{i t}}{p M A_{i t}}\right) \ln C A P_{i t}+\sum_{n} \beta_{n} Z_{i t}^{n}+\sum_{t} \beta_{t} D_{t} \\
& \quad+v_{i t}+u_{i t}
\end{aligned}
$$

where $\mathrm{Y}_{\mathrm{it}}$ is the quantity of water delivered by utility $\mathrm{i}$ at time $t, p_{L}$ is labour price, $p_{M A}$ the material price and CAP the stock of capital. The $\mathrm{n}$ environmental factors are contained within the vector $\mathrm{Z}, \mathrm{n}=\mathrm{PUM}$, DENS, $\mathrm{D}_{\text {MALT }}$, $D_{\text {HALT }}$, MAXTEMP and $D_{\text {PREC }}$. PUM is the share of water that has to be pumped, DENS is customer density and $\mathrm{D}_{\text {MALT }}$ and $\mathrm{D}_{\text {HALT }}$ are dummy variables that equal one if the utilities are located in medium or high altitudes, as opposed to low altitude regions. MAXTEMP is the maximum 30 days average temperature over the year and $D_{\text {PREC }}$ is a dummy indicating whether the utility was exposed to a high precipitation event during a given year. Finally, $\mathrm{D}_{03}$ to $\mathrm{D}_{09}$ are time dummies for the years 2003-2009.

All monetary amounts are deflated to 2003 constant Swiss francs using the producer's price index of the Federal Office of Statistics. Cost and factor prices are normalized by the material price to guarantee homogeneity in input prices and $\beta_{\mathrm{jn}}=\beta_{\mathrm{nj}}$ imposes symmetry. Given that some properties of the translog cost function are not imposed (in particular concerning its curvature), they should be verified ex post, based on the estimated coefficients.

To estimate Eq. (2), we use two alternative stochastic frontier estimation techniques that differ in the way $u_{i t}$ is defined. ${ }^{3}$ They are random effects models, because there is very little or no within-group variability in many of the variables. The drawback of these models is the assumption that individual effects are uncorrelated with the regressors, because random noise and inefficiency as well as unmeasured heterogeneity are distributed independently of each other and the regressors.

\footnotetext{
${ }^{2}$ Possible interactions between output and exogenous factors seem intuitively appealing, as the impact of environmental conditions on variable cost may vary with utility size. The model was also estimated including interaction terms between output and exogenous factors. However, none of these proved to be statistically significant and a likelihood ratio test rejected the model including interactions in favour of the restricted one.

${ }^{3}$ For a detailed description of the different estimation methods, see Kumbhakar and Lovell (2000) and Greene (2005a, b).
} 
First, to investigate the issue of observed heterogeneity and its impact on cost and efficiency, we use the Pitt and Lee (1981) (PL) stochastic cost frontier estimated by maximum likelihood (ML). In this approach, the inefficiency term is time invariant, and the distribution of the inefficiency and random noise terms are the following:

$\ln \mathrm{VC}_{\mathrm{it}}=\mathrm{c}\left(\mathrm{y}_{\mathrm{it}}, \mathrm{p}_{\mathrm{it}}, m_{i t}, z_{i t} ; \beta\right)+\mathrm{v}_{\mathrm{it}}+\mathrm{u}_{\mathrm{i}}$

$\mathrm{u}_{\mathrm{i}} \sim N^{+}\left[0, \sigma_{u}^{2}\right]$

$\mathrm{v}_{\text {it }} \sim N\left[0, \sigma_{v}^{2}\right]$

We will refer to this model as "Model I with environment". An obvious shortcoming of this model is the time-invariant inefficiency term. Therefore, our second approach relaxes this restrictive assumption by using the Battese and Coelli (1992) (BC) model, where:

$\mathrm{u}_{\mathrm{it}}=U_{i} \exp \left(-\eta\left(t-T_{i}\right)\right)$

$\mathrm{v}_{\mathrm{it}} \sim N\left[0, \sigma_{v}^{2}\right]$

where $\eta$ is a parameter to be estimated and $U_{\mathrm{i}}$ are independent and identically distributed as an $N^{+}\left[0, \sigma_{u}^{2}\right]$ distribution. This model has the advantage of allowing time variation in the inefficiency term. Indeed, $\mathrm{u}_{\mathrm{it}}$ varies through time; however the random component $U_{\mathrm{i}}$ is still constant through time.

As discussed above, observed heterogeneity can enter the model through various avenues, one being the cost frontier itself, while in the other the exogenous factors influence the distribution of the inefficiency term. As a robustness check of the results, we have introduced heterogeneity in the variance of the inefficiency term. ${ }^{4}$ This model offers the advantage of both correcting for heteroscedasticity in $\mathrm{u}_{\mathrm{i}}$ and providing an alternative method to account for heterogeneity (Kumbhakar and Lovell 2000). ${ }^{5}$ We will refer to this model as "Model II with environment". The distribution of the one-sided error term becomes (with $\gamma$ the coefficients to be estimated):

$\mathrm{u}_{\mathrm{i}} \sim N^{+}\left[0, \sigma_{u i}^{2}\right]$

$\sigma_{u i}^{2}=\exp \left(z_{i} \gamma\right)$

The other important issue to address in (2) is the treatment of unobserved heterogeneity. Both the PL and the BC models suppose that unobserved time-invariant heterogeneity is entirely inefficiency. This can be problematic especially under very heterogeneous conditions, where many of the

\footnotetext{
${ }^{4}$ We thank an anonymous referee for this suggestion.

5 As only time-invariant exogenous factors are accommodated in this model, the mean values of the variables are used for time-varying environmental variables. This is not problematic for density and the share of pumped water, which display very little within group variability. However, it entails some loss of information for both meteorological factors that vary from year to year.
}

differences in environmental conditions cannot be observed and as a result inefficiency may be overestimated. A potential solution to this issue lies in the estimation of the "true random effect" (TRE) model by Greene (2005b). This model introduces a stochastic term denoted $\mathrm{w}_{\mathrm{i}}$ that captures timeinvariant unmeasured heterogeneity and separates it from the inefficiency measure $\mathrm{u}_{\mathrm{it}}$. It addresses both the problems of time-invariant firm specific heterogeneity and time-varying inefficiency:

$\ln \mathrm{VC}_{\mathrm{it}}=w_{i}+\mathrm{c}\left(\mathrm{y}_{\mathrm{it}}, \mathrm{p}_{\mathrm{it}}, m_{i t}, z_{i t} ; \beta\right)+\mathrm{v}_{\mathrm{it}}+\mathrm{u}_{\mathrm{i}}$

$\mathrm{u}_{\mathrm{it}} \sim N^{+}\left[0, \sigma_{u}^{2}\right]$

$\mathrm{v}_{\text {it }} \sim N\left[0, \sigma_{v}^{2}\right]$

$\mathrm{w}_{\mathrm{i}} \sim N\left[0, \sigma_{w}^{2}\right]$

By assuming none of the unobserved persistent differences to be inefficiency, the TRE model can in turn lead to an underestimation of inefficiency levels, and the true inefficiency may thus lie somewhere between the PL model on one side and Greene's TRE on the other side. The TRE is estimated by simulated maximum likelihood using 300 quasi-random Halton draws. Inefficiency terms $u_{i t}$ are estimated indirectly, using the Jondrow et al. (1982) estimator to obtain estimates of the conditional expectation of $\mathrm{u}_{\mathrm{it}}$ given the observed values of $\varepsilon_{\mathrm{it}}$ (with $\left.\varepsilon_{i t}=v_{i t}+u_{i t}\right),{ }^{6} E\left[u_{i t} \mid \varepsilon_{i t}\right]$. For the $i^{\text {th }}$ firm in year $t$, cost inefficiency $\mathrm{CI}$ is defined as:

$\mathrm{CI}_{\mathrm{it}}=\exp \left(\mathrm{u}_{\mathrm{it}}\right)$

Cost inefficiency estimates measure the distance that separates the firm from the cost frontier. The score of a perfectly cost-efficient water utility is one and its $u_{i t}$, which accounts for inefficiency, is zero. Consequently, the perfectly efficient water utility operates on the cost frontier. At the other extreme, an infinite cost inefficiency score would occur if $u_{i t} \rightarrow \infty$. More generally, the higher the CI coefficient is, the higher the cost-inefficiency of the firm.

\section{Data description}

We use a database of the SGWA, which originally contains information on approximately 400 water utilities, over the period 2000-2009. The database results from a detailed survey done by the SGWA every 5 years (thus in our case in 2000 and in 2005), and a shorter survey which is conducted each year (SGWA 2002-2010). It gives information on the type of the water production process, the network characteristics, customer attributes and the costs of water supply. The survey is not compulsory and therefore many utilities do not participate every year or give incomplete

\footnotetext{
${ }^{6}$ For the TRE model, $\varepsilon_{i t}=v_{i t}+u_{i t}+w_{i}$.
} 
answers, resulting in a high number of missing values. In the original database, the missing value issue is particularly important for the years 2000 and 2001, especially for the variables needed to measure labour cost. These years are thus excluded from our sample. After eliminating some aberrant values that were misreported, our final sample is an unbalanced panel containing data on 141 water distribution utilities and a total of 745 observations over the years 2002-2009. The final sample does only include about $5 \%$ of the about 3,000 existing Swiss water utilities. However, the utilities included in the sample supplied water to about $27 \%$ of the Swiss population on average over the years 2002-2009. This implies that larger water utilities are overrepresented. Also, bigger utilities have a slightly lower probability to be missing in the dataset than smaller ones, so that missing values are not random. Nonetheless, the utilities included in the database still differ widely in terms of size, structure, water resources, geological characteristics of the distribution area, production processes and weather conditions and are situated all across Switzerland. As already mentioned, most of them are public companies owned by the municipalities, some acting as well as electricity and gas distributors.

The output is measured as the yearly total quantity of water delivered in thousands of cubic meters. As shown in Table 1, it varies between 22 thousand and 65 million cubic meters of drinking water. The number of customers goes from about 200 for the smallest utility to more than 450,000 for the biggest. These figures highlight the large diversity of the drinking water distribution utilities included in the sample in terms of size. Variable costs are calculated by summing labour costs and all material expenses, including energy costs. Given the differences of the utilities in terms of size, the spread of variable cost is not surprising. However, average variable costs vary from $0.15 \mathrm{CHF}$ per cubic meter of water to $3.3 \mathrm{CHF}$ per cubic meter ${ }^{7}$. These large differences emphasize the importance of understanding the determinants of the costs of drinking water utilities, and in particular of separating cost differences due to inefficiency from those stemming from heterogeneity in the operating environment.

The price of labour is defined as total labour cost divided by the number of employees in full time equivalent $(\text { FTE })^{8}$. The second input is materials, which includes energy costs, water treatment products, material costs and all remaining "other expenses". We follow Garcia and Thomas (2001) in constructing a price variable for

\footnotetext{
7 In 2003, 1 CHF $=0.74$ USD $=0.66$ EURO.

${ }^{8}$ We have information about FTE in 2009 only. For the previous years, the survey reports the total number of employees working part time and the total number of employees working full time only. We assume that the FTE of part-time employees in 2009 is constant over the whole period. For those utilities for which we do not have FTE for
}

materials by dividing it by the quantity of water delivered. This procedure seems acceptable, given the heterogeneity of the costs included in the material and other expenses categories and the lack of access to more pertinent data. To lessen the impact of outliers on estimation results and to avoid problems due to misreported values, the labour price values lower than the $1 \%$ quantile and higher than the $99 \%$ quantile of labour costs in Switzerland in the water distribution sector are eliminated from the sample, as are the $1 \%$ smallest and the $1 \%$ largest material price values.

Capital stock can be measured either by using a capacity measure or a cost measure applying the perpetual inventory technique, as for example in Nelson (1989). Although the latter method is theoretically more appropriate, we cannot apply it due to the lack of data. Therefore, as in other studies (e.g. Nauges and van den Berg 2008) we use the total network length as measure for the capital stock. Data on network length is collected every 5 years only (in our case in 2000 and 2005). We have interpolated the data assuming a linear investment path, which is a reasonable assumption, given that network length is relatively stable in the period under observation. For 2009 and for those utilities which have missing data in 2000 or in 2005 , we estimate the network length with lagged network length and total investment in the network during the period as regressors. ${ }^{9}$

Six exogenous factors are included in the analysis. First, we consider the proportion of pumped water over total water adduction. We expect that utilities with larger shares of pumped water have higher energy and treatment cost. Indeed, the water that does not have to be pumped is spring water, which in Switzerland is generally of very high quality and needs less treatment than ground or surface water. In our sample, while some small utilities use only spring water that flows by gravity, an average of approximately $70 \%$ of the water has to be pumped.

Second, we include customer density, which is measured as the number of customers per meter of network. Customer density is integrated as an environmental factor rather than including the number of customers directly as

\footnotetext{
Footnote 8 continued

2009, part-time employees correspond to the median FTE of utilities of comparable size. To test the possible impact of this variable on our results, we have estimated the cost frontier and inefficiency scores using alternative labour cost data from the Swiss Federal Office of Statistics based on the median gross salary in 7 Swiss regions. Results are very similar and the main conclusions are unchanged. Therefore, we use the much more precise utility-specific cost of labour data instead of the regional median salaries.

9 The estimated equation is the following:
}

$\ln \left(\right.$ networklength $\left._{t}\right)=0.69(0.43)+0.81(0.05) \ln \left(\right.$ networklength $\left._{t-1}\right)$ $+0.11(0.04) \ln ($ sum of investments)

With SEs in brackets. $\mathrm{R}^{2}=0.87$. 
Table 1 Descriptive statistics

\begin{tabular}{|c|c|c|c|c|c|c|}
\hline Variable & Measurement unit & Mean & Median & SD & Min & $\operatorname{Max}$ \\
\hline Variable cost & CHF (thousands) & 2,927 & 897 & 8,379 & 12 & 61,700 \\
\hline Output & $1,000 \mathrm{~m}^{3} /$ year & 2,787 & 924 & 7,803 & 22 & 65,411 \\
\hline Labour price & 1,000 CHF/worker/year & 104 & 101 & 36 & 40 & 294 \\
\hline Material price & $\mathrm{CHF} / 1,000 \mathrm{~m}^{3}$ water/year & 636 & 543 & 422 & 35 & 2,653 \\
\hline Network & $\mathrm{km}$ & 129 & 76 & 214 & 8 & 1,624 \\
\hline Customers & Thousands & 21.8 & 8.8 & 58.5 & 0.2 & 456.9 \\
\hline Density & Customers/network unit & 0.13 & 0.12 & 0.06 & 0.02 & 0.36 \\
\hline Pumped water & Part of total water delivered & 0.71 & 0.86 & 0.33 & 0 & 1 \\
\hline Medium altitude & Dummy & 0.51 & 1 & 0.5 & 0 & 1 \\
\hline High altitude & Dummy & 0.25 & 0 & 0.43 & 0 & 1 \\
\hline Max. 30 days temperature & Degrees & 26.1 & 26 & 2.6 & 17.4 & 32.5 \\
\hline Heavy 2 days precipitation & Dummy & 0.12 & 0 & 0.32 & 0 & 1 \\
\hline Number of observations & 745 & & & & & \\
\hline Utilities & 141 & & & & & \\
\hline
\end{tabular}

Data source: SGWA and MeteoSwiss

an output dimension. Indeed, the inclusion of additional output dimensions would entail adding not only the variables, but also their squares and interaction terms, as the functional form is a translog. This would lead to the loss of degrees of freedom and possibly to multicollinearity problems, as the number of customers is highly correlated with both output and capital stock. This problem does not arise with customer density. However, the model including the number of customers as an output dimension instead of customer density as an environmental factor is estimated as a robustness check of our results. The main results and conclusions remain unchanged. ${ }^{10}$

The impact of customer density on costs can be positive or negative. On the one hand, distributing water to more densely populated areas can be more costly since water has to be extracted outside these areas and consequently transported (Saal and Reid 2004), increasing not only capital expenses, but also energy and other operating costs. Further, Torres and Morrison (2006) note that higher density may call for more complex connections and thus cause pressure or maintenance problems. On the other hand, distributing water in less populated areas could be expensive because it requires long distribution pipelines (Torres and Morrison 2006) and thus increases capital cost. Also, more pumping is needed to bring the drinking water to the customers and energy expenses are thus heightened. Estimation of the cost frontier has to determine if the positive or the negative effect prevails.

The third and fourth environmental factors relate to the altitude at which the water utility is situated. Dummies are used to differentiate lowland utilities (i.e. those below

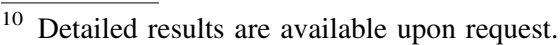

$460 \mathrm{~m}$ ) from those at medium or high altitude (between 460 and 670 and above $670 \mathrm{~m}$, respectively). There is a variety of reasons why costs could be related to altitude. Firstly, the need for pumping may be influenced by altitude (Corton 2011). As it is already controlled for by the inclusion of a variable measuring the share of pumped water, these impacts should be limited. Secondly, challenging topography can lead to higher costs for the building and maintenance of infrastructure. Additionally, cold winter temperatures or landslides may damage infrastructure and lead to an increase in labour and material expenditure. One should note that these dummy variables may also capture regional heterogeneity like geographic differences that the model does not address.

The remaining exogenous variables are weather-related factors and are collected from MeteoSwiss: maximum mean temperature over 30 days and heavy precipitation events. We use $\mathrm{X}-\mathrm{Y}$ geographic coordinates to determine the closest weather station for each water distribution utility and then associate the two weather-related events to it. These environmental factors are included to assess the impact of extreme weather events on drinking water distribution cost, as it is expected they will occur more frequently in Switzerland due to climate change (OcCC 2008).

Maximum 30 days temperature is expected to increase variable cost for a number of reasons. Firstly, episodes of high temperatures can impact water quality by affecting oxygen content of the water and favour algae growth (Gander 2009). They can lead to taste and odour problems and the water may require additional treatment. Secondly, higher temperatures are expected to cause an increase in drinking water demand and thus lead to higher variable 
cost. Further, high summer temperatures may lead to peaks in water demand and small water distribution utilities that are not interconnected with others may encounter problems to meet drinking water demand if episodes of high temperature come along with drought, as was the case during the very hot and dry summer of 2003 (ProClim 2005). Maximum 30 days temperature varies across weather stations due to different altitudes and locations across Switzerland. Year to year patterns are similar across stations, with a peak in 2003, a year that saw an exceptionally warm and dry summer, as well as high temperatures in 2006, due to very hot July temperatures.

The occurrence of high precipitation events during 1 year is measured with a dummy variable. MeteoSwiss defines various levels of threats associated with precipitations, on a scale from 1 to 5 . To define high precipitation we consider degree 4 and 5 threats only, as these are the levels at which important floods and landslides that potentially damage infrastructure can occur. The dummy indicating high precipitation takes the value 1 if there has been during the year an episode where precipitation exceeded $110 \mathrm{~mm}$ in 2 days, which is a degree 4 threat as defined by MeteoSwiss. The 2-day time-frame was chosen after estimating the model with variables for 1, 2 and 3 day episodes. 1 day seems to be too short a time frame, as the estimated coefficients are not statistically significant. As 3-day coefficients are slightly less significant than those measuring 2-day episodes, we include the latter in the cost frontier. This variable is expected to increase cost. Indeed, high precipitation events can result in water quality deterioration due for example to sewage overflow and call for additional treatment. In extreme cases they might damage the utilities' infrastructure and cause higher expenses for repairs, increasing labour and material as well as capital expenses, although the latter would impact total and not variable cost. In our sample, about $12 \%$ of observations have at least one heavy precipitation event over the period.

\section{Results and discussion}

The variable cost frontier (2) is estimated using the PL (1981) and Greene (2005b) models. We also estimate the BC (1992) model. However, a likelihood ratio test of the $\mathrm{BC}$ model with time-varying inefficiency against the PL model favours the latter. ${ }^{11}$ Indeed, with $\eta$ equal to zero, the normal half-normal BC model reduces to the PL (1981) model. This result might be due to the relatively short time-

\footnotetext{
11 Time-variance was tested only in the model where heterogeneity is directly included in the cost frontier. Indeed, the BC model could not be estimated with heterogeneity included in the inefficiency distribution as models did not converge.
}

span of the panel or the modelling of time-varying inefficiency, where the random component $U_{i}$ is still constant through time. Table 2 reports the likelihood ratio tests of the translog (2) against a Cobb-Douglas functional form. The test statistic has a Chi squared distribution and equals $-2\left(L_{r}-L_{L}\right)$, where $L_{r}$ and $L_{0}$ are respectively the log likelihoods of the restricted (Cobb-Douglas) and the unrestricted (translog) models. Degrees of freedom equal the number of restrictions imposed on the restricted model. As reported in Table 2, likelihood ratio tests reject the Cobb-Douglas in favour of the translog in all models. ${ }^{12}$ Furthermore, models excluding exogenous variables are rejected when tested against their counterpart that accounts for the environment, emphasizing the importance to include heterogeneity in the estimations.

We also estimate a nested PL model including observed heterogeneity both in the cost frontier and the variance of the inefficiency term. None of the estimated $\gamma$ coefficients were significant at $10 \%$ levels, and a likelihood ratio test rejects the nested model with heteroscedasticity in inefficiency in favour of a model accounting for environmental factors in the cost frontier only. This indicates that the inclusion of heterogeneity in the cost frontier rather than in the inefficiency distribution appears as a more suitable solution for Swiss drinking water utilities.

Table 3 displays the estimation of Eq. (2) and a variation that excludes environmental factors for the PL as well as the Greene TRE models. Estimation results for the PL model with heterogeneity in the variance of the inefficiency term (Model II) are included as robustness check of the results. The estimated coefficients of the traditional variables included in the cost frontier possess the expected signs and are similar across the PL and TRE models. Differences arise mostly in the estimated efficiency scores that will be discussed later.

We choose the median water utility as reference point for local approximation, thus all regressors except the dummies are normalized by their sample medians. This allows for the direct interpretation of the first order coefficients as cost elasticities evaluated at the median. Thus, referring for example to the TRE model with environment, a $1 \%$ increase in the quantity of drinking water distributed results in an about $0.75 \%$ increase in variable cost, ceteris paribus. The coefficients of the output and of the price variables are statistically significant and have the expected positive sign in all models. Although theory suggests the capital stock should have a negative impact on variable cost (Antonioli and Filippini 2001), the estimated coefficient is positive and significant. This result is observed very frequently in the literature, see for instance Bottasso and

\footnotetext{
12 Detailed results of the estimation of the Cobb-Douglas cost frontier are available upon request.
} 
Table 2 Likelihood ratio tests

\begin{tabular}{llrrr}
\hline & Restrictions & PL (Model I) & PL (Model II) & Greene TRE \\
\hline Translog with environment versus translog without environment & 6 & $43.8^{* * *}$ & $15^{* *}$ & $58.2^{* * *}$ \\
Translog with environment versus Cobb-Douglas with environment & 6 & $148.8^{* * *}$ & $149.3^{* * *}$ & $179.9^{* * *}$ \\
\hline
\end{tabular}

Statistically significant at $1 \% * * *, 5 \% * *$

Table 3 Estimation results

\begin{tabular}{|c|c|c|c|c|c|c|c|c|c|c|}
\hline \multirow[b]{3}{*}{$\beta_{\mathrm{Y}}$} & \multicolumn{6}{|l|}{ Pitt and Lee } & \multicolumn{4}{|l|}{ Greene TRE } \\
\hline & \multicolumn{2}{|c|}{ Environment (Model I) } & \multicolumn{2}{|c|}{ Without environment } & \multicolumn{2}{|c|}{ Environment (Model II) } & \multicolumn{2}{|c|}{ With environment } & \multicolumn{2}{|c|}{ Without environment } \\
\hline & $0.7651 * * *$ & 0.0305 & $0.8346 * * *$ & 0.0236 & $0.7964 * * *$ & 0.0198 & $0.7467 * * *$ & 0.0077 & $0.8523 * * *$ & 0.0054 \\
\hline$\beta_{\mathrm{PL}}$ & $0.2989 * * *$ & 0.0090 & $0.2962 * * *$ & 0.0094 & $0.2993 * * *$ & 0.0080 & $0.3041 * * *$ & 0.0036 & $0.2992 * * *$ & 0.0037 \\
\hline$\beta_{\mathrm{CAP}}$ & $0.2422 * * *$ & 0.0346 & $0.1699 * * *$ & 0.0252 & $0.1824 * * *$ & 0.0226 & $0.2665 * * *$ & 0.0094 & $0.1566 * * *$ & 0.0074 \\
\hline$\beta_{Y Y}$ & -0.0024 & 0.0356 & $-0.0638 *$ & 0.0365 & $-0.0818 * *$ & 0.0407 & 0.0159 & 0.0119 & $-0.0426 * * *$ & 0.0115 \\
\hline$\beta_{\mathrm{PLPL}}$ & $0.1100 * * *$ & 0.0122 & $0.1061 * * *$ & 0.0125 & $0.1050 * * *$ & 0.0085 & $0.0919 * * *$ & 0.0045 & $0.0906 * * *$ & 0.0047 \\
\hline$\beta_{\text {CAPCAP }}$ & $0.1525 * * *$ & 0.0507 & $0.1289 * * *$ & 0.0484 & $0.1316 * *$ & 0.0565 & $0.1239 * * *$ & 0.0217 & $0.0826 * * *$ & 0.0212 \\
\hline$\beta_{\mathrm{YPL}}$ & $-0.0242 *$ & 0.0128 & $-0.0257 * *$ & 0.0131 & $-0.0235 * *$ & 0.0117 & $-0.0218 * * *$ & 0.0059 & $-0.0220 * * *$ & 0.0060 \\
\hline$\beta_{\mathrm{YCAP}}$ & -0.0358 & 0.0351 & -0.0001 & 0.0356 & 0.0003 & 0.0431 & $-0.0533 * * *$ & 0.0145 & 0.0017 & 0.0139 \\
\hline$\beta_{\text {PLCAP }}$ & $0.1072 * * *$ & 0.0179 & $0.1135 * * *$ & 0.0181 & $0.1137 * * *$ & 0.0124 & $0.1033 * * *$ & 0.0074 & $0.1047 * * *$ & 0.0077 \\
\hline$\beta_{\text {PUM }}$ & $0.0630 * *$ & 0.0311 & & & & & $0.0900 * * *$ & 0.0088 & & \\
\hline$\beta_{\text {DENS }}$ & $0.1316^{* * *}$ & 0.0337 & & & & & $0.1780 * * *$ & 0.0087 & & \\
\hline$\beta_{\text {MALT }}$ & $0.0911 * * *$ & 0.0359 & & & & & $0.0495 * * *$ & 0.0075 & & \\
\hline$\beta_{\text {HALT }}$ & $0.1319 * * *$ & 0.0424 & & & & & $0.1179 * * *$ & 0.0104 & & \\
\hline$\beta_{\text {MAXTEMP }}$ & $0.5183 * * *$ & 0.1884 & & & & & $0.5215 * * *$ & 0.0429 & & \\
\hline$\beta_{\text {PREC }}$ & $0.0353 * * *$ & 0.0132 & & & & & $0.0290 * * *$ & 0.0101 & & \\
\hline$\beta_{03}$ & $-0.0971 * * *$ & 0.0330 & -0.0210 & 0.0139 & -0.0192 & 0.0218 & $-0.0977 * * *$ & 0.0188 & -0.0180 & 0.0174 \\
\hline$\beta_{04}$ & $-0.0294 * *$ & 0.0147 & -0.0168 & 0.0139 & -0.0170 & 0.0192 & $-0.0309 * *$ & 0.0146 & -0.0178 & 0.0145 \\
\hline$\beta_{05}$ & $-0.0332 * *$ & 0.0133 & $-0.0329 * *$ & 0.0134 & $-0.0333 * *$ & 0.0166 & $-0.0342 * * *$ & 0.0132 & $-0.0347 * * *$ & 0.0133 \\
\hline$\beta_{06}$ & $-0.0850 * * *$ & 0.0283 & -0.0229 & 0.0151 & -0.0237 & 0.0215 & $-0.0802 * * *$ & 0.0166 & -0.0149 & 0.0158 \\
\hline$\beta_{07}$ & 0.0297 & 0.0198 & 0.0019 & 0.0151 & -0.0010 & 0.0201 & 0.0225 & 0.0142 & -0.0022 & 0.0144 \\
\hline$\beta_{08}$ & 0.0153 & 0.0169 & -0.0066 & 0.0155 & -0.0082 & 0.0215 & 0.0048 & 0.0145 & -0.0140 & 0.0147 \\
\hline$\beta_{09}$ & -0.0043 & 0.0151 & -0.0047 & 0.0151 & -0.0074 & 0.0163 & -0.0197 & 0.0127 & -0.0153 & 0.0123 \\
\hline$\alpha$ & $-0.4298 * * *$ & 0.0487 & $-0.3243 * * *$ & 0.0202 & -0.3242 & 0.0223 & $-0.2023 * * *$ & 0.0153 & $-0.0978 * * *$ & 0.0108 \\
\hline$\gamma_{\mathrm{PUM}}$ & & & & & 0.6700 & 0.4443 & & & & \\
\hline$\gamma_{\text {DENS }}$ & & & & & $0.8256 * *$ & 0.3490 & & & & \\
\hline$\gamma_{\text {MALT }}$ & & & & & 0.3875 & 0.5946 & & & & \\
\hline$\gamma_{\text {HALT }}$ & & & & & 0.6880 & 0.8465 & & & & \\
\hline$\gamma_{\text {MAXTEMP }}$ & & & & & 2.5508 & 3.5838 & & & & \\
\hline$\gamma_{\text {PREC }}$ & & & & & -0.0144 & 1.4674 & & & & \\
\hline Sigma u & 0.3512 & & 0.3773 & & 0.2468 & & 0.1291 & & 0.1311 & \\
\hline Sigma v & 0.0882 & & 0.0900 & & 0.0892 & & 0.0401 & & 0.0429 & \\
\hline LL & 531.38 & & 509.487 & & 516.97 & & 563.86 & & 534.77 & \\
\hline
\end{tabular}

Statistically significant at $1 \%{ }^{* * *}, 5 \% * *$ and $10 \% *$; SEs in italics

Conti (2008) and Garcia and Thomas (2001). This problem may result from several causes. Firstly, the positive coefficient may be due to a multicollinearity problem between the network length and output variables (Filippini 1996). Indeed, the correlation between output and network length is high, a remark that would probably apply for most capital measures. Secondly, network length may be considered an output characteristic, which would explain the positive impact on cost. Thirdly, as suggested by Cowing and Holtmann (1983) this result may also indicate high levels of overcapitalisation. When discussing variable cost functions that are increasing in capital, these authors point 
out that "although this condition is clearly inconsistent with long-run equilibrium, it is not inconsistent with a short-run equilibrium if current operating conditions are substantially different from those prevailing, or expected, when the original capital decision was made." This statement is particularly relevant for water distribution utilities, where the need to meet all demand and very long planning horizons for modification of capital stock often result in excess capacity. In such case, a total cost function would be mis-specified and the estimated coefficients biased. This article would benefit from the estimation of the frontiers with other capital stock measures to shed more light on this issue. However, there is no data available on other variables that could serve as a proxy for the capital stock.

Concerning the environmental variables, the coefficient associated with the share of pumped water is positive and statistically significant at least at the $5 \%$ level in both models that include heterogeneity in the frontier. As expected, a higher share of pumped water relates to increased variable costs. This result is in line with Bottasso and Conti (2003), who associate higher levels of average pumping head with increased cost inefficiency.

A higher population density also possesses a significant positive impact on variable costs. Possible congestion, pressure and maintenance problems thus seem to override the potential cost savings of distributing drinking water to more densely populated areas. Population density is found to increase cost in other studies as well, such as Saal and Reid (2004), where density is found to increase variable cost, or Fraquelli and Moiso (2005), who associate higher density with increased total cost inefficiency. This result is also compatible with the findings of Farsi and Filippini (2009), who conclude that population density has a positive impact on the marginal cost of water distribution.

Estimation results further show variable cost to be significantly higher in high and medium altitude regions than in the plain. The drawbacks of a difficult topography and adverse climatic conditions seem to offset possible advantages of being located at a higher altitude.

The coefficient of the dummy measuring the occurrence of heavy rainfall has the expected positive sign and is statistically significant at the $1 \%$ level for both the PL and the TRE models, indicating that very heavy rain is linked to increased variable cost. Drinking water utilities that experience an episode of heavy precipitation during the year display variable costs about $3 \%$ higher than a utility that is not subjected to such an episode. Heavy rainfall and consequent floods or landslides can damage the infrastructure or contaminate the drinking water. This may not only result in higher total, but also variable cost, as for example expenditures in labour and material could increase due to repair works and cleaning of the pipes.

Maximum 30 days temperature has a relatively high and statistically significant impact. In the TRE model, a $1 \%$ increase in the maximum 30 days average temperature results in $0.52 \%$ higher variable costs. This result is compatible with the findings of Renzetti and Dupont (2009), who show maximum weekly summer temperature to increase the inefficiency of water distribution utilities. The positive relationship between high summer temperature and variable cost might have several causes. First, higher temperatures can result in peaks in drinking water demand, thus increasing the ratio of maximum daily water demand to mean daily water demand. Next, heat waves are often associated to drought and high demand coupled to lowered supply may increase the cost of drinking water utilities. An increase in future summer temperature related to climate change could thus heighten variable costs of drinking water distribution. Lastly, the coefficient could be capturing time or regional effects not otherwise accounted for in the cost frontier. Time dummies and the inclusion of altitude in the regression should at least partially control for these effects, as in Switzerland the between-utility variation in temperature is linked to altitude. ${ }^{13}$

When environmental factors are included in the variance of the error term, only population density has a statistically significant impact. The exogenous factors do explain some of the variance in the inefficiency, since a likelihood ratio test rejects the simple PL model against the heteroscedastic one. However, as mentioned above, the heteroscedastic model is rejected in favour of the homoscedastic version of the model when a nested model including heterogeneity both in the frontier and in the inefficiency is estimated.

The estimated cost frontiers should possess the economic properties summarised in Table 4. Homogeneity in input prices has been imposed prior to estimation. Wellbehaved cost frontiers should also be monotonically increasing in input prices and output and concave in input prices. The estimated cost shares are positive for all observations in all models, implying that the condition of the frontier being monotonically increasing in input prices is well respected. Further, the estimated frontiers are all monotonically increasing in output because $\frac{\partial \ln C V_{i t}}{\partial \ln q_{i t}}$ is positive for all data points. In addition, they should be concave in input prices, meaning that the hessian matrix should be negative semi-definite. This property is respected at a majority-over $90 \%$ - of all data points in all the estimated models. Still, since concavity is not verified at every data point, some caution should be taken when interpreting the estimation results.

Table 5 summarizes the estimated inefficiency scores for the different models. Scores of all the models including environmental factors and their counterparts excluding them

\footnotetext{
13 The inclusion of other regional dummies (for example accounting for statistical regions in Switzerland) also produced a significant positive coefficient for temperature.
} 
Table 4 Properties of the cost frontier

\begin{tabular}{|c|c|c|c|c|c|}
\hline & \multicolumn{5}{|c|}{ Percentage of observations for which the property is verified } \\
\hline & \multicolumn{3}{|l|}{ Pitt and Lee } & \multicolumn{2}{|l|}{ Greene TRE } \\
\hline & Environment (Model I) & Environment (Model II) & Without env. & Environment & Without env. \\
\hline Homogeneity of degree one in input prices & Imposed & Imposed & Imposed & Imposed & Imposed \\
\hline Monotonically increasing in input prices $(\%)$ & 100 & 100 & 100 & 100 & 100 \\
\hline Monotonically increasing in output (\%) & 100 & 100 & 100 & 100 & 100 \\
\hline Concave in input prices $(\%)$ & 94.90 & 95.57 & 95.30 & 98.93 & 98.79 \\
\hline
\end{tabular}

Table 5 Estimated inefficiency scores

\begin{tabular}{llllll}
\hline & Mean & Median & SD & Minimum & Maximum \\
\hline $\begin{array}{c}\text { PL with env. } \\
\text { (Model I) }\end{array}$ & 1.378 & 1.355 & 0.254 & 1.011 & 2.295 \\
$\begin{array}{c}\text { PL with env. } \\
\text { (Model II) }\end{array}$ & 1.444 & 1.355 & 0.319 & 1.010 & 2.418 \\
$\begin{array}{c}\text { PL without } \\
\text { environment }\end{array}$ & 1.416 & 1.338 & 0.285 & 1.010 & 2.510 \\
$\begin{array}{c}\text { TRE with } \\
\text { environment } \\
\text { TRE without } \\
\text { environment }\end{array}$ & 1.106 & 1.080 & 0.089 & 1.013 & 2.025 \\
\hline
\end{tabular}

are very close. Indeed, mean inefficiency scores in the various PL models vary between 38 and $44 \%$, while they are virtually identical in the TRE models. In the PL specification, accounting for observed heterogeneity reduces the standard deviation and the maximum values of inefficiency scores, pointing that particularly high inefficiency may be related to unfavourable environmental conditions. Unsurprisingly, inefficiency scores from the TRE models, estimated to be a little below $11 \%$, are much lower than from the PL models. These differences result from the way unobserved heterogeneity is treated: it is attributed to inefficiency in the PL model, while Greene's TRE captures timeinvariant unobserved heterogeneity separately. Indeed, other than the theoretical construction of the model, empirical applications show Greene's TRE and "true fixed effects" (TFE) models to give much higher efficiencies than models that assume all time-invariant unobserved heterogeneity to be inefficiency. This is particularly true in network industries, where environmental conditions evolve slowly or not at all in time. Illustrations can among others be found in the Slovenian and Italian water sectors (Filippini et al. 2007 and Abrate et al. 2011), Swiss multi-utilities (Farsi and Filippini 2009) or Finnish electricity distribution (KopsakangasSavolainen and Svento 2008). This has two important consequences for our analysis. First, estimated inefficiency is much lower in the TRE compared to the PL model. Second, inefficiency scores of models that include environmental factors are quite close to those that do not when estimated with the TRE, as four of the environmental factors, namely population density, the percentage of pumped water and the two altitude related dummies are constant or change very little in time. These findings are similar to results found in comparable studies for other sectors in the literature, for example by Growitsch et al. (2011), who analyse the performance of Norwegian electricity distribution networks accounting for geographic and weather related factors.

One of the most important outputs of SFA is the ranking of the utilities. This is particularly true if SFA is applied to benchmark utilities for regulation purposes, as inefficiency scores would be used to establish the best and worst performing utilities. The rankings of drinking water utilities resulting from models including environmental factors and their counterparts excluding them are also close. Indeed, Table 6 shows that Spearman rank correlations are about 0.91 between the PL model without environmental factors and the PL model that includes heterogeneity directly in the frontier (Model I) and are even as high as 0.98 between the PL model without environment and its heteroscedastic counterpart (Model II). In the TRE model, Spearman correlations are also very high and rankings are thus very similar. Close efficiency scores and high rank correlations among scores derived from methods accounting or not for observed heterogeneity support recent findings for Spanish water utilities by Picazo-Tadeo et al. (2009b) who reject the hypothesis that rankings based on initial technical efficiency and scores adjusted for operating environment and luck differ, even though the scores themselves change. On the other hand, in the studies by Renzetti and Dupont (2009) for Ontario and for the non-parametric approach by Zschille and Walter (2012) for Germany, efficiency scores vary substantially when accounting for exogenous factors and importantly, correlations between efficiency scores adjusted for the environment and those that are not are low. These studies based on non-parametric methods offer quite contrasting conclusions, highlighting that the impact of exogenous factors may depend not only on estimation techniques, but is also case- and country-specific.

On the contrary, the differences in the rankings are very important between the PL and the TRE models. Indeed, 
Table 6 Spearman rank correlations

Statistically significant at $1 \% * * *, 5 \% * *$ and $10 \% *$

\begin{tabular}{llllll}
\hline & PL (Model I) & PL (Model II) & PL no. env. & TRE env. & TRE no. env. \\
\hline PL (Model I) & 1 & & & & \\
PL (Model II) & $0.86^{* * *}$ & 1 & & & \\
PL no. env. & $0.91^{* * *}$ & $0.98^{* * *}$ & 1 & 1 & \\
TRE env. & $0.14^{* * *}$ & $0.11^{* * *}$ & $0.12^{* * * *}$ & 1 & \\
TRE no. env. & $0.13^{* * *}$ & $0.12^{* * *}$ & $0.13^{* * *}$ & $0.96^{* * *}$ & 1 \\
\hline
\end{tabular}

Spearman correlations of 0.14 between the PL model and TRE show that the choice of one model over the other does not only influence the value of inefficiency scores, but also substantially changes the efficiency ranking of utilities and could thus have a very important impact in a regulatory context.

Figures 1 and 2 highlight these findings. Figure 1 shows the distribution of inefficiency scores for the estimated models, while Fig. 2 compares estimated inefficiency scores directly. Estimated inefficiencies are similar when the points are close to a $45^{\circ}$ line. Both figures confirm the two results already discussed. Firstly, estimated inefficiencies differ a lot between the models that capture timeinvariant unobserved heterogeneity in the inefficiency and the TRE which treats it separately. In the latter case, unsurprisingly, inefficiency is much lower. Secondly, estimated inefficiencies and, very importantly, ranks are slightly affected by the inclusion of the environmental factors. The impact of including or not environmental factors is however much lower than the one of choosing how to treat unobserved heterogeneity.

The impact on rankings of the choice of whether or not to include environmental factors into the estimated cost frontier is finally illustrated by the individual utility rankings in Table 7. This table reports the rankings of the top ten ranked utilities in the PL model with environmental factors directly in the cost frontier (Model I) for the year 2009. Rankings between models that include or not exogenous factors are very close in most cases. However, differences in rankings are much more pronounced between the PL and the TRE models. For example, the most efficient utility in the PL models ranks 97 th or 98th in the TRE. These results again emphasize the importance of the treatment of unobserved heterogeneity in analysing the performance of water utilities as this choice can seriously alter both estimated inefficiency scores and rankings. If stochastic frontier models are to be used for regulation in the Swiss water distribution industry, the most important choice seems thus about how to account for non-observed rather than observed heterogeneity.

\section{Conclusion}

This paper estimates the efficiency of Swiss drinking water utilities using two alternative stochastic frontier estimation
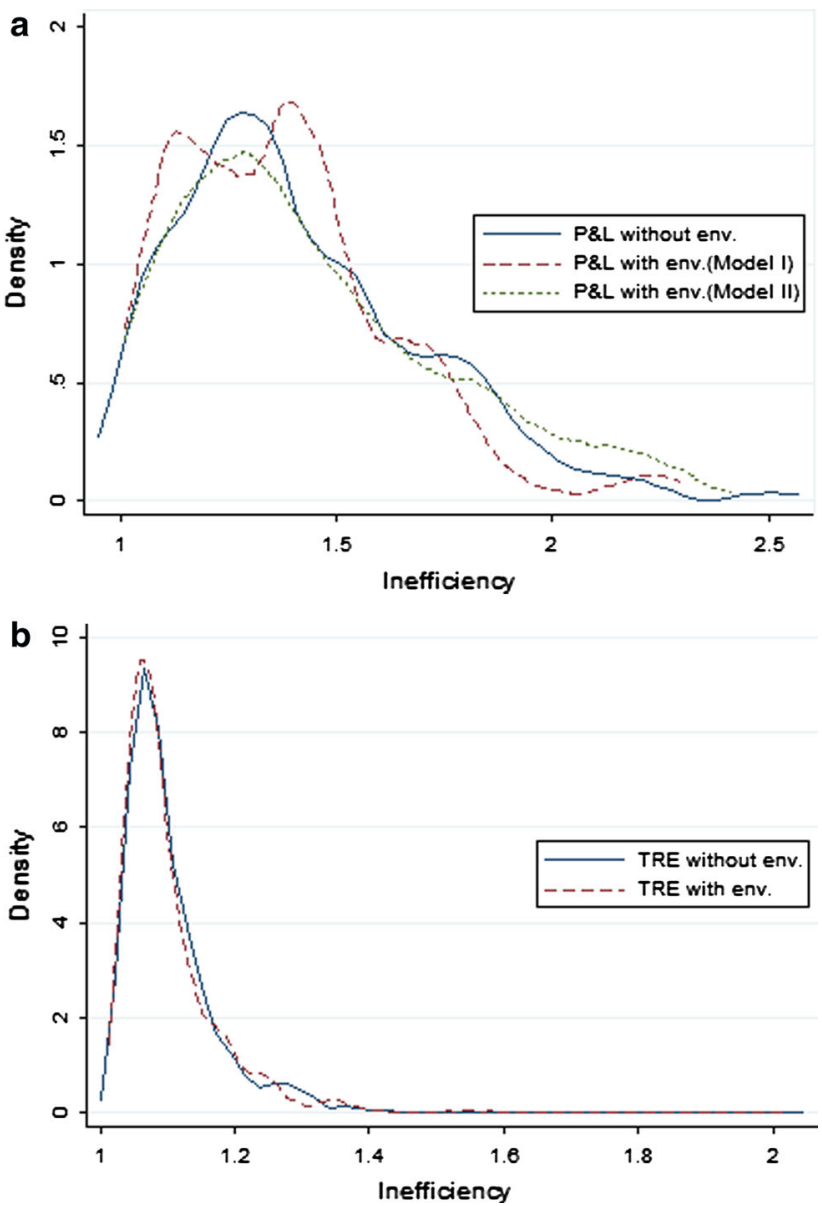

Fig. 1 Density of inefficiency scores

techniques and accounting for exogenous factors. Results show that the share of pumped water, population density, altitude, maximum 30 days average temperature and heavy precipitation events have a significant impact on variable cost. The impact of heat waves and heavy precipitation is particularly interesting, as both summer temperature and the occurrence of high precipitation episodes are predicted to increase in Switzerland due to climate change (OcCC 2008). Further, likelihood ratio tests emphasize the importance to include observed environmental heterogeneity in the estimations. Rankings provided by models accounting for the environment and their counterparts that do not differ a little 

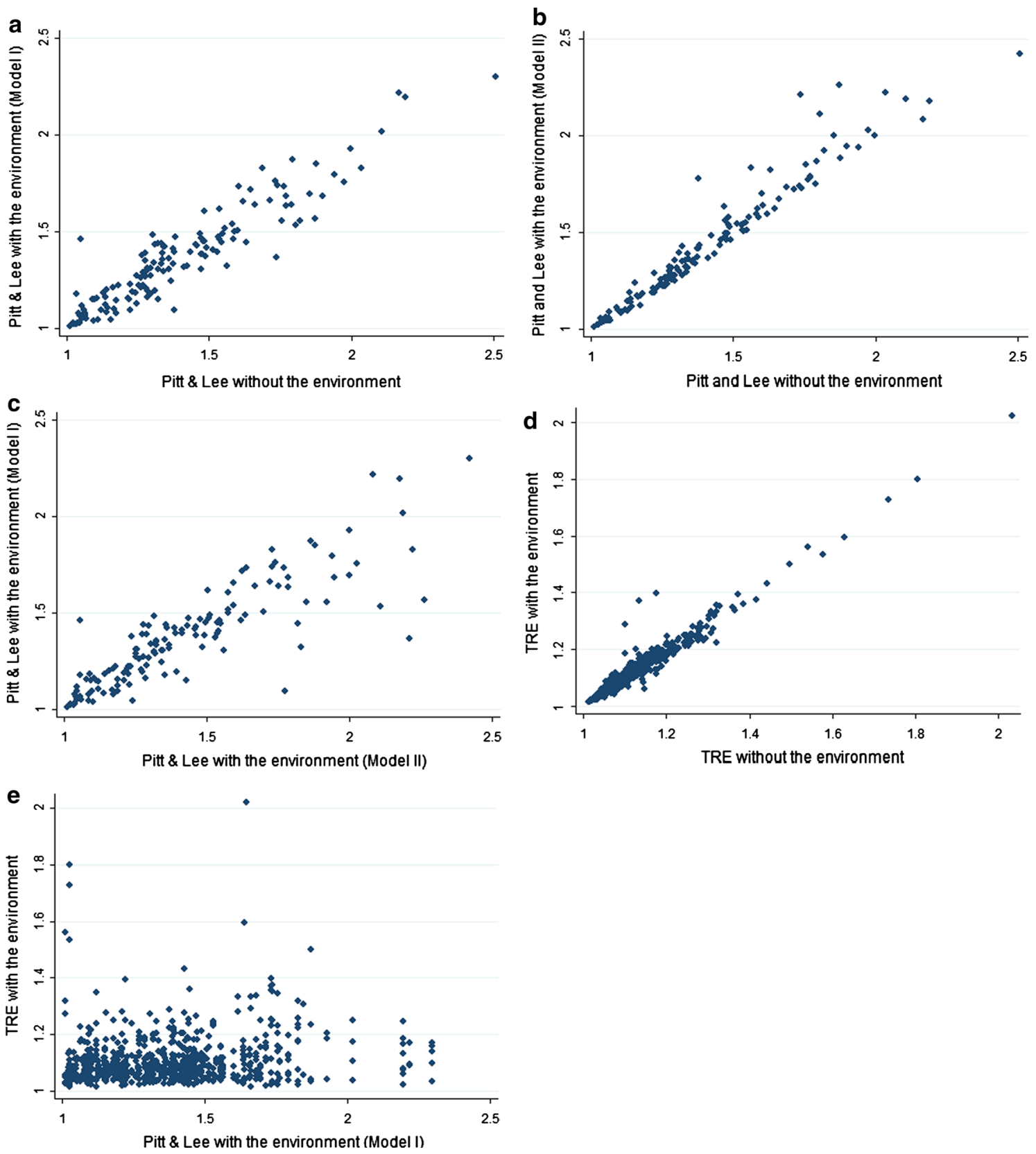

Fig. 2 Comparison of inefficiency scores

in the Pitt and Lee model, while rankings are similar in the TRE model. The efficiency rank of utilities is however very different in the Pitt and Lee vs. Greene's TRE models. Therefore, our results show the statistically significant impact of environmental factors on the cost of water distribution utilities, but more importantly, they highlight the importance of paying attention to the way unobserved heterogeneity is treated. The Swiss drinking water distribution utilities are very heterogeneous and operate in very different conditions, most of which vary very little through time. Due to data and econometric constraints, it is impossible to include variables that would account for all these differences. This favours Greene's TRE as the model of choice, even though it might underestimate inefficiency. Wide differences in ranking of the utilities show the sensitivity of results to modelling choices and consequently emphasize that if SFA is to be used for regulation, alternative models should be tested and that even though econometric benchmarking can be an effective tool, it should be complemented by further analysis. 
Table 7 Ranking of individual utilities in 2009

\begin{tabular}{|c|c|c|c|c|c|}
\hline & \multicolumn{3}{|l|}{ PL } & \multicolumn{2}{|l|}{ TRE } \\
\hline & $\begin{array}{l}\text { With } \\
\text { (Model I) }\end{array}$ & $\begin{array}{l}\text { With } \\
\text { (Model II) }\end{array}$ & Without & With & Without \\
\hline Utility 1 & 1 & 1 & 1 & 98 & 97 \\
\hline Utility 2 & 2 & 2 & 2 & 97 & 98 \\
\hline Utility 3 & 3 & 3 & 4 & 14 & 11 \\
\hline Utility 4 & 4 & 14 & 11 & 23 & 20 \\
\hline Utility 5 & 5 & 10 & 14 & 75 & 81 \\
\hline Utility 6 & 6 & 30 & 19 & 64 & 53 \\
\hline Utility 7 & 7 & 5 & 9 & 25 & 44 \\
\hline Utility 8 & 8 & 4 & 5 & 63 & 31 \\
\hline Utility 9 & 9 & 11 & 8 & 27 & 13 \\
\hline Utility 10 & 10 & 19 & 22 & 69 & 72 \\
\hline
\end{tabular}

Acknowledgements We thank the Swiss Gas and Water Industry Association (SGWA) for providing the data. We are grateful for the helpful comments from three anonymous referees, David Maradan, Philippe Thalmann and the participants of the XII European Workshop on Efficiency and Productivity Analysis, 21-24 June 2011, especially David Saal. This research has been financed by the Network of competencies in economics and management of the University of Applied Sciences Western Switzerland (HES SO) and by National Centre of Competence in Research (NCCR) Climate. The findings, interpretations, conclusions and any remaining errors are the authors' own.

\section{References}

Abbott M, Cohen B (2009) Productivity and efficiency in the water industry. Utili Policy 17:233-244

Abrate G, Erbetta F, Fraquelli G (2011) Public utility planning and cost efficiency in a decentralized regulation context: the case of the Italian integrated water service. J Prod Anal 35(3):227-242

Aigner D, Lovell CAK, Schmidt P (1977) Formulation and estimation of stochastic frontier production functions models. J Econ 6:21-37

Antonioli D, Filippini M(2001) The use of variable cost function in the regulation of the Italian water industry. Utili Policy 10:181-187

Baranzini A (1996) Structure des coûts des stations d'épuration en Suisse et gestion efficace des eaux usées. Swiss J Econ Stat 132(4):515-538

Battese GE, Coelli TJ (1992) Frontier production functions, technical efficiency and panel data: with application to paddy farmers in India. J Prod Anal 11:251-273

Battese GE, Coelli TJ (1995) A model for technical inefficiency effects in a stochastic frontier production function for panel data. Empir Econ 20:325-332

Berg S, Marques R (2011) Quantitative studies of water and sanitation utilities: a literature survey. Water Policy 12(5):591-606

Bottasso A, Conti M (2003) Cost inefficiency in the English and Welsh water industry: an heteroskedastic stochastic cost frontier approach. Economics discussion papers 573, University of Essex, Department of Economics

Bottasso A, Conti M (2008) Scale economies, technology and technical change in the water industry: evidence from the English water only sector. Reg Sci Urban Econ 39(2):138-147

Carvalho P, Marques RC (2011) The influence of the operational environment on the efficiency of water utilities. J Environ Manag 92(10):2698-2707
Carvalho P, Marques RC, Berg S (2012) A meta-regression analysis of benchmarking studies on water utilities market structure. Utili Policy 21:40-49

Christensen LR, Jorgenson DW, Lau LJ (1973) Transcendental logarithmic production frontiers. Rev Econ Stat 55:28-45

Coelli T, Perelman S, Romano E (1999) Accounting for environmental influences in stochastic frontier models: with application to international airlines. J Prod Anal 11:251-273

Conti M (2005) Ownership relative efficiency in the water industry: a survey of the international empirical evidence. Econ Internazionale 58(3):273-306

Corton ML (2011) Sector fragmentation and aggregation of service provision in the water industry. J Prod Anal 35:159-169

Cowing TG, Holtmann AG (1983) Multiproduct short run hospital cost functions: empirical evidence and policy implications from cross-section data. South Econ J 49:637-653

De Witte K, Dijkgraaf E (2010) Mean and bold: on separating merger economies from structural efficiency gains in the drinking water sector. J Oper Res Soc 61(2):222-234

De Witte K, Marques RC (2010) Designing performance incentives, an international benchmark study in the water sector. Central Eur J Oper Res 18(2):189-220

De Witte K, Saal D (2010) Is a little sunshine all we need? On the impact of sunshine regulation on profits, productivity and prices in the Dutch drinking water sector. J Regul Econ 37(3):219-242

Di Cosmo V (2012) Ownership. To be published in Journal of Industry, Competition and Trade, Scale Economies and Efficiency in the ItalianWater Sector

Farsi M, Filippini M (2009) An analysis of cost efficiency in Swiss multi-utilities. Energy Econ 31(2):306-315

Filippini M (1996) Economies of scale and utilization in the Swiss electric power distribution industry. Appl Econ 28:543-550

Filippini M, Hrovatin N, Zoric J (2007) Cost efficiency of Slovenian water distribution utilities: an application of stochastic frontier methods. J Prod Anal 29:169-182

Fraquelli G, Moiso V (2005) Cost efficiency and economies of scale in the Italian water industry. Conference of the Società italiana di economia pubblica. Pavia, 15-16 September

Gallant R (1981) On the bias in flexible functional forms and an essentially unbiased form: the fourier flexible form. J Econ 15(2):211-245

Gander B (2009) Climate change and water suppliers: informations and adaptation strategies. Gwa 89:241-249

Garcia S, Thomas A (2001) The structure of municipal water supply costs: application to a panel of French local communities. J Prod Anal 16:5-29

Garcia S, Moreaux M, Reynaud A (2007) Measuring economies of vertical integration in network industries: an application to the water sector. Int J Ind Organ 25(4):791-820

Greene WH (2005a) Fixed and random effects in stochastic frontier models. J Prod Anal 23:7-32

Greene WH (2005b) Reconsidering heterogeneity in panel data estimators of the stochastic frontier model. J Econ 126:269-303

Growitsch C, Jamasb T, Wetzel H (2011) Efficiency effects of observed and unobserved heterogeneity: evidence from Norwegian electricity distribution networks. Energy Economics, Available online 4 November 2011, ISSN 0140-9883, 10.1016/ j.eneco.2011.10.013. (http://www.sciencedirect.com/science/article/ pii/S0140988311002635)

Huang CJ, Liu JT (1994) Estimation of a non-neutral stochastic frontier production function. J Prod Anal 5:171-180

Jondrow J, Materov I, Lovell K, Schmidt P (1982) On the estimation of technical inefficiency in the stochastic frontier production function model. J Econ 19:233-238

Kilchmann A (2003) Distributeurs d'eau et analyse concurrentielle. Gwa 6:411-418 
Kopsakangas-Savolainen M, Svento R (2008) Estimation of costeffectiveness of the Finnish electricity distribution utilities. Energy Econ 30(2):212-229

Kumbhakar SC, Lovell CAK (2000) Stochastic frontier analysis. Cambridge University Press, Cambridge

Kumbhakar SC, Ghosh S, McGuckin JT (1991) A generalized production frontier approach for estimating determinants of inefficiency in US dairy farms. J Bus Econ Stat 9(3):279-286

Luís-Manso P (2005) Water institutions and management in Switzerland. Lausanne: Ecole Polytechnique Fédérale de Lausanne, College of Management of Technology, MIR-Report-2005-001

Marques RC, Berg SV, Shinji Y (2011) Performance benchmarking analysis of Japanese water utilities. University of Florida, Department of Economics, PURC Working Paper

Meeusen W, van den Broeck J (1977) Efficiency estimation from Cobb-Douglas production functions with composed error. Int Econ Rev 18(2):435-444

Nauges C, van den Berg C (2008) Economies of density, scale and scope in the water supply and sewerage sector: a study of four developing and transition economies. J Regul Econ 34:144-163

Nelson RA (1989) On the measurement of capacity utilization. J Indus Econ 37(3):273-286

OcCC (2008). Le climat change-que faire? Le nouveau rapport des Nations Unies sur le climat (GIEC 2007) et ses principaux résultats dans l'optique de la Suisse. OcCC-Organe consultatif sur les changements climatiques, Berne, 47 pp. ISBN: 978-3907630-34-1

Picazo-Tadeo A, Sáez-Fernández F, González-Gómez F (2009a) The role of environmental factors in water utilities technical efficiency. Empirical evidence from Spanish companies. Appl Econ 41:615-628
Picazo-Tadeo A, Sáez-Fernández F, González-Gómez F (2009b) Accounting for operating environments in measuring water utilities' managerial efficiency. Service Indus J 29:761-773

Pitt MM, Lee LF (1981) The measurement and sources of technical inefficiency in the indonesian weaving industry. J Dev Econ 9:43-64

ProClim (2005) Canicule de l'été 2003. Rapport de synthèse, ProClim, Berne. ISBN 978-3-907630-16-7

Reifschneider D, Stevenson R (1991) Systematic departures from the frontier: a framework for the analysis of firm inefficiency. Int Econ Rev 32:715-723

Renzetti S, Dupont D (2003) Ownership and performance of water utilities. Greener Manag Int 42(1):9-19

Renzetti S, Dupont D (2009) Measuring the technical efficiency of municipal water suppliers: the role of environmental factors. Land Econ 85:627-636

Saal D, Reid S (2004) Estimating opex productivity growth in English and welsh water and sewerage companies 1993-2003. Research paper 0434. Aston Business School, Ashton University

SGWA (2002-2010). Résultats statistiques des distributeurs d'eau en Suisse: années 2000 à 2009. SGWA, Zurich

Torres M, Morrison PC (2006) Driving forces for consolidation or fragmentation of the U.S. water utility industry: a cost function approach with endogeneous output. J Urban Econ 59:104-120

Walter M, Cullmann A, von Hirschhausen C, Wand R, Zschille M (2009) Quo vadis efficiency analysis of water distribution? A comparative literature review. Utili Policy 17:225-232

Zschille M, Walter M (2012) The performance of German water utilities: a (semi)-parametric analysis. Appl Econ 44:3749-3764 